\title{
Surface Properties of Me/Si Structures Prepared by Means of Self-Ion Assisted Deposition
}

\author{
I. TASHLYKOV ${ }^{a, *}$, P. ŻUKOWski ${ }^{b}$, O. MikHALKOVICH ${ }^{a}$ AND S. BARAishUK ${ }^{a}$ \\ ${ }^{a}$ Belarusian State Pedagogical University, 18, Sovetskaja Str., 220050 Minsk, Belarus \\ ${ }^{b}$ Lublin University of Technology, Nadbystrzycka 38a, 20-618 Lublin, Poland
}

In this paper a composite structure, topography, wettability and nanohardness of a (100) Si surface modified by means of ion-assisted deposition of metal (Me) coatings in conditions of a self-irradiation are discussed.

DOI: $10.12693 /$ APhysPolA.125.1306

PACS: 61.72.uf, 82.80.-d, 62.20.Qp

\section{Introduction}

The deposition of thin metal films on silicon wafers has both scientific and practical interest. It allows to create insulating or conductive layers, lyophilic or lyophobic surface in different fluid products $[1,2]$. Xe ion implantation into silicon is widely used to control damage of its structure [3, 4]. It is remained little knowledge about processes of mass transfer in the silicon coating applied to self-ion assisted deposition (SIAD), and the influence of pre-implantation of xenon on diffusion processes in silicon during the metal coating deposition. In order to control the properties of coatings on the substrate surface it is necessary for diagnostic coating/substrate systems. In this paper a composite structure, topography, wettability, and nanohardness of a surface (100) Si modified by means of ion-assisted deposition of metal $(\mathrm{Ti}, \mathrm{Co})$ coatings in conditions of a self-irradiation are discussed.

\section{Experimental section}

The system employed for the coating deposition has been described in detail elsewhere [5] and consists, essentially, of a vacuum chamber to which a resonance vacuum arc source (RVAS) with metal (titan or cobalt) electrodes to produce a mixture of $\mathrm{Me}$ atoms and $\mathrm{Me}^{+}$ions attached is. Substrate (silicon wafers) was floated to a negative potential with respect to the source of $7 \mathrm{kV}$ to accelerate the ion species. The SIAD system was pumped by a conventional diffusion pump and attained during film deposition a base pressure of $10^{-2} \mathrm{~Pa}$.

To investigate atom mixing processes at an interface region of a coating/substrate it is useful to know a position of initial surface of substrate (PISS). For this purpose we implanted $\mathrm{Xe}^{+}$ions in the part of substrates. The energy of ions was 10 or $40 \mathrm{keV}$, doses - in range $1 \times 10^{14}-2.7 \times 10^{15} \mathrm{Xe} / \mathrm{cm}^{2}$.

The composition of the coating/substrate structures and the damage of irradiated substrate were investigated using the Rutherford backscattering/channeling spectroscopy (RBS/RCS). The energy of the $\mathrm{He}^{+}$ions

\footnotetext{
*corresponding author; e-mail: tashl@bspu.unibel.by
}

was $2.0 \mathrm{MeV}$ and the energy resolution of analyzing system was $25 \mathrm{keV}$. The experimental RBS data for concentration against depth were compared with data from the RUMP code simulation [6]. The average value of the projected range of elements in the matrix were calculated using a computer program TRIM-89 [7].

Roughness parameters of virgin silicon substrate and substrate with Me coatings were measured using atomic force microscope NT-206 and corresponding software.

The wettability of the surface of the coating was determined by the values of the contact angle, which is measured by sitting drop method. The droplet volume was $9.3 \mu \mathrm{l}$.

The nanoindentation data from coated systems were used for calculation of the hardness and elastic modulus using load and displacement sensing indentation experiments. During the measurements, the curve of loading and unloading were obtained, which were processed by the method of Oliver-Pharr [8].

The thickness of the deposited coating has a value in the range $180-200 \mathrm{~nm}$.

\section{Results and discussion}

Figure 1 shows the profiles of the depth distribution structure components obtained during the application of cobalt films on $\mathrm{Si}$, without the xenon irradiation (a) and with it (b).

It is found that the coating composition comprises metal atoms, hydrogen, carbon, oxygen, and silicon. The appearance in the studied coatings $\mathrm{O}, \mathrm{C}, \mathrm{H}$ we associate with the deposition on the surface of the coating during its growth together with the atoms Co, hydrocarbon fraction and $\mathrm{O}$ from the residual vacuum in the target chamber, steam-pumped by the diffusion oil pump. Analyzing the results, Fig. 1a and b, let us note that the carbon and oxygen atoms penetrate into the silicon substrate by about $30 \mathrm{~nm}$ deeper if coating/substrate was pretreated by xenon ions. Cobalt atoms penetrate into the silicon to a depth of many more times deeper than the projected range calculated by the program TRIM. In the $\mathrm{Si}$ wafer pre-implanted with $\mathrm{Xe}^{+}$ions penetration depth of the cobalt atoms increases by $\approx 120 \mathrm{~nm}$. The concentration of cobalt atoms on a comparable depth increases by a factor of 1.5 . This effect can be explained by radiation-enhanced diffusion of Me atoms during deposi- 


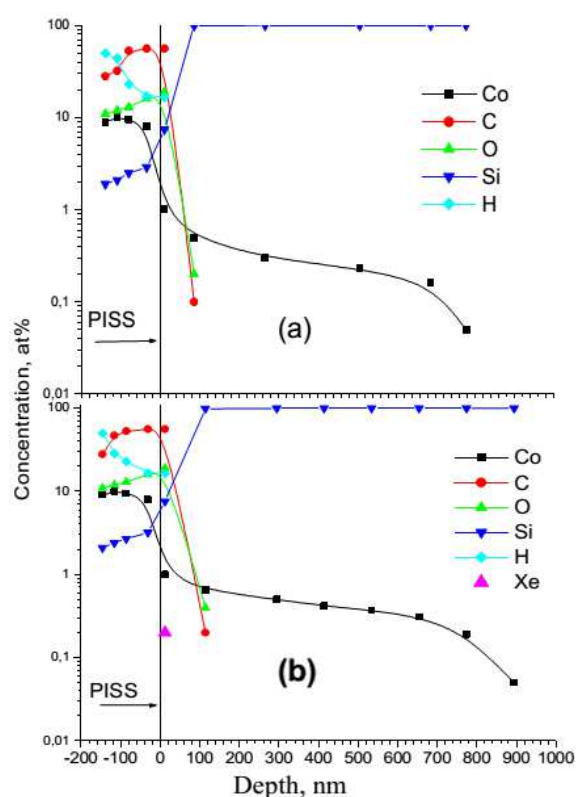

Fig. 1. Relative content of species in SIAD Co thin film on silicon: (a) only SIAD process, (b) SIAD process after Xe irradiation.

tion of coatings on Xe-radiated silicon. Comparison of align and random spectra from the virgin and Me coated (100) $\mathrm{Si}$ is done to determine the position of the metal atoms in the crystal lattice of silicon at different depths using known technique [9].

The character of the distribution of the cobalt atoms in silicon which are substitutions, curve $\mathrm{Co}_{\text {sub }}$, and interstitials, curve $\mathrm{Co}_{\text {int }}$, suggests a plausible mechanism of Me atoms diffusion. In the silicon near PISS $(\approx 10 \mathrm{~nm})$ the greatest damage of the crystal lattice is generated, and there is observed a sharp decrease in the concentration of cobalt atoms. This is explained due to the fact that with increase of number of interstitial silicon atoms there is decrease of the possible migration paths of Co atoms along the silicon interstitials in the silicon lattice. At greater depths the proportion of cobalt atoms being in the crystal lattice increases, reaching a value of $40 \%$ at about $780 \mathrm{~nm}$. Analysis of the distribution of the cobalt atoms in silicon, previously irradiated $\mathrm{Xe}^{+}$ions with the energy of $10 \mathrm{keV}$ and doses value of $3 \times 10^{14} \mathrm{Xe} / \mathrm{cm}^{2}$, Fig. 2b, suggests that the mechanism of Co diffusion using substitution is essential. Pre-irradiation of silicon by xenon ions leads to greater damage of the Si structure and to increase of the cobalt atoms in substitute positions. This effect has dose dependence. Irradiation of silicon with $\mathrm{Xe}^{+}$ions leads to decrease of proportion of Co interstitials from $86 \%$ to $30 \%$ while $\mathrm{Xe}^{+}$ions dose increases from $1 \times 10^{14} \mathrm{Xe} / \mathrm{cm}^{2}$ to $2.7 \times 10^{15} \mathrm{Xe} / \mathrm{cm}^{2}$ at a depth of penetration $\approx 90 \mathrm{~nm}$.

Let us note that the physical processes of $\mathrm{Ti} /$ substrate structures formation is qualitatively comparable to the processes that occur during the deposition of cobalt on silicon surfaces.

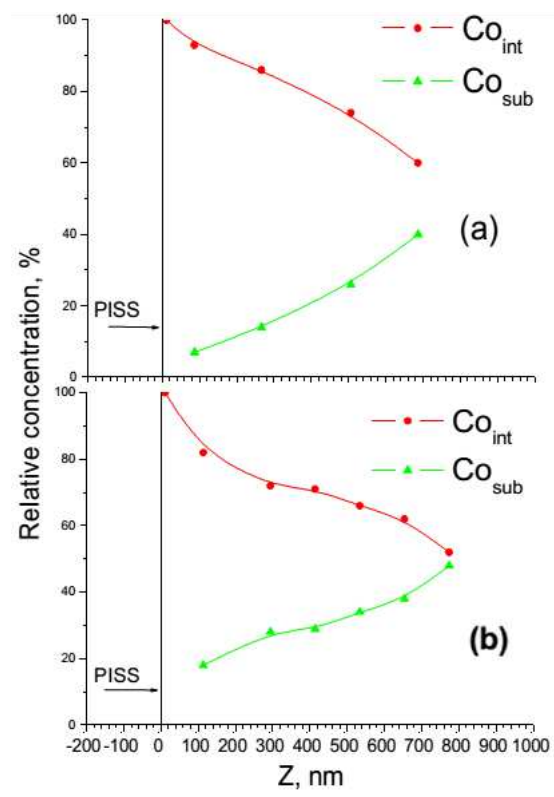

Fig. 2. The distribution of the cobalt atoms in silicon of $\mathrm{Co} / \mathrm{Si}$ structures, formed by: (a) only SIAD process, (b) SIAD process with the pre-implanted $\mathrm{Xe}^{+}, E_{\mathrm{xe}}=$ $10 \mathrm{keV}, D=3 \times 10^{14} \mathrm{~cm}^{-2}$.

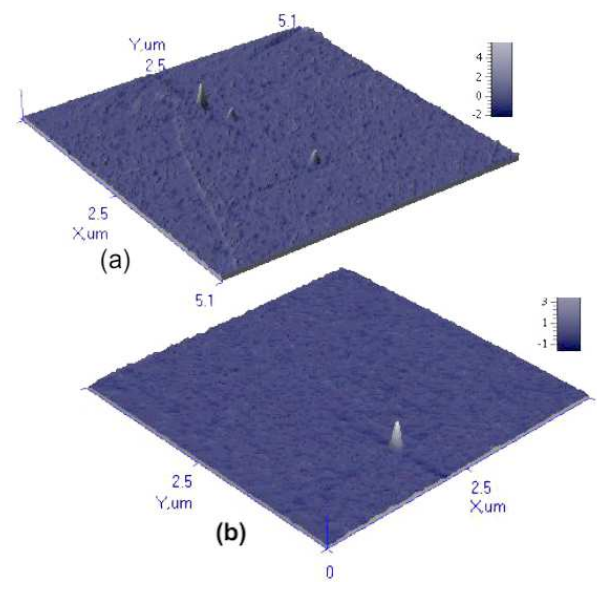

Fig. 3. Three-dimensional AFM surface morphology of silicon with Ti coating: (a) only SIAD process, (b) SIAD process after Xe irradiation.

In the study of topography of systems coating/substrate and the pure silicon site $5 \times 5 \mu \mathrm{m}^{2}$ were chosen. According to 3D images of the surface topography of titanium coating in Fig. 3 one can conclude that the high quality surface on silicon is generated.

Figure 4 shows photographs of water droplets on the surface of the Ti coating.

Parameters of the surfaces of the deposited coatings are shown in Table.

As follows from Table xenon irradiation does not cause significant changes of distilled water wettability. Generally, there are the changes of the roughness parameters within nanometer range in our case. That is why it can 


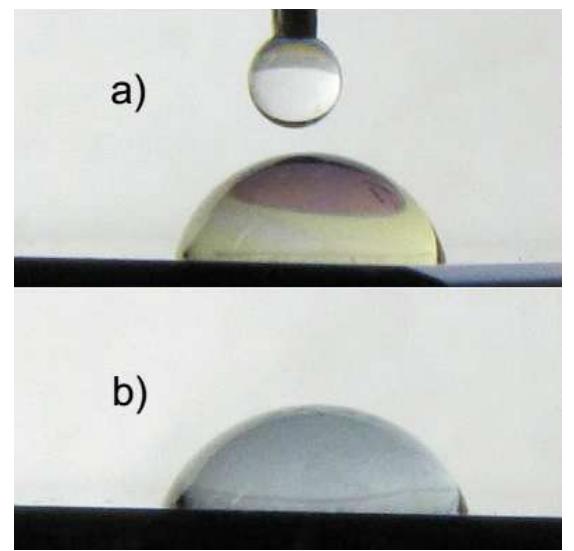

Fig. 4. Pictures of water droplets on the surface of the $\mathrm{Ti}$ coating on the silicon: (a) only SIAD process, (b) SIAD process after Xe irradiation.

TABLE

Parameters of surfaces of the Ti and Co coatings deposited on silicon.

\begin{tabular}{c|c|c|c|c}
\hline \hline \multirow{2}{*}{ Parameter } & \multicolumn{2}{|c|}{ Ti coating } & \multicolumn{2}{c}{ Co coating } \\
\cline { 2 - 5 } & $\begin{array}{c}\text { without } \\
\text { irradiation }\end{array}$ & $\begin{array}{c}\text { with } \\
\text { irradiation }\end{array}$ & $\begin{array}{c}\text { without } \\
\text { irradiation }\end{array}$ & $\begin{array}{c}\text { with } \\
\text { irradiation }\end{array}$ \\
\hline $\begin{array}{c}\text { contact } \\
\text { angle [deg] }\end{array}$ & 77.8 & 78.4 & 60.5 & 59.3 \\
$R_{\text {ave }}[\mathrm{nm}]$ & 0.123 & 0.158 & 0.114 & 0.113
\end{tabular}

be concluded that SIAD process of Me thin films on silicon is appropriated for microelectronics.

The results of measuring of nanohardness of the formed $\mathrm{Me} / \mathrm{Si}$ structures are shown in Fig. 5.

The hardness of the surface of Ti coatings (thickness of $50 \mathrm{~nm}$ layer) increases 4 -fold and we observe 4.5-fold increase when applied to cobalt. With increase of the depth of the indentation integral nanohardness of the structures coating/substrate approaches to the nanohardness of silicon.

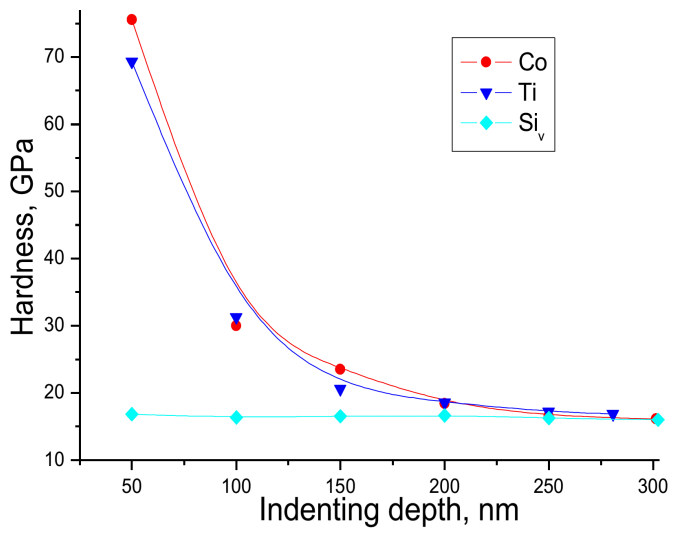

Fig. 5. The dependence of the surface nanohardness of the $\mathrm{Me} / \mathrm{Si}$ structures on the depth of the indentation.

\section{Conclusion}

We have shown that Me coatings produced by means of SIAD have a multi-component structure. Thin films deposited on silicon consist of $\mathrm{Me}, \mathrm{C}, \mathrm{O}, \mathrm{Si}$, and $\mathrm{H}$. The high content of $\mathrm{C}, \mathrm{O}$, and $\mathrm{H}$ arises, we suppose, because of the poor vacuum used, and it allows capture of oxyhydrocarbons onto the growing film and accumulation of them under irradiation with the accelerated $\mathrm{Me}^{+}$ ions. Silicon appears in the coatings due to an out-diffusion process from the bulk. Deep penetration of Me atoms into silicon and appearance of $\mathrm{Si}$ atoms in coatings are attributed to radiation-enhanced diffusion processes during self-ion assisted deposition of thin cobalt and titanium based films upon silicon. Implantation of $\mathrm{Xe}^{+}$ions in substrate before deposition of Me coatings promotes radiation-enhanced diffusion of components in $\mathrm{Me} / \mathrm{Si}$ structures.

The experimental results confirm the possibility to control the mass transfer in Si introduction to the structure of radiation defects. With the use of scanning probe microscopy high quality and low surface roughness obtained structures $\mathrm{Ti} / \mathrm{Si}$ and $\mathrm{Co} / \mathrm{Si}$, indicating the possibility of surface roughness control systems $\mathrm{Me} / \mathrm{Si}$, are used for various functional elements. It is found that pre-irradiation of silicon by xenon ions does not lead to a significant change in the wettability of the surface of the obtained structures. The study of the surface nanohardness of the coatings showed that the SIAD process creates coating hardness which is comparable to the hardness of diamond-like films. Ion-assisted deposition process of $\mathrm{Me}$ coatings on silicon may be applied in microelectronics.

\section{References}

[1] S.M. Baraishuk, V.F. Gremenok, V.V. Tuljev, I.S. Tashlykov, Phys. Chem. Treat. Mater. 1, 66 (2011).

[2] I.S. Tashlykov, S.M. Baraishuk, O.M. Mikhalkovich, I. Antonovich, Przeglad Elektrotechniczny 84, 111 (2008) (in Polish).

[3] N.A. Poklonski, N.I. Gorbachuk, Vo Quang Nha, S.V. Shpakovski, V.A. Filipenia, V.A. Skuratov, A. Wieck, Interact. Radiat. Solids 10, 146 (2013).

[4] I.S. Tashlykov, O.M. Michalkovich, Phys. Chem. Treat. Mater. 5, 49 (2008).

[5] I.S. Tashlykov, I.M. Belyi, O.G. Bobrovich, S. Kalbitzer, O. Meyer, G.K. Wolf, B. Enders, Nucl. Instrum. Methods Phys. Res. B 80-81, 98 (1993).

[6] L. Doolittle, Nucl. Instrum. Methods Phys. Res. B 15, 227 (1986).

[7] J.F. Ziegler, J.P. Biersack, U. Littmark, The Stopping and Range of Ions in Solids, Vol. 1, Pergamon Press, Oxford 1985, p. 321.

[8] W.C. Oliver, G.M. Pharr, J. Mater. Res. 7, 1564 (1992).

[9] E. Bögh, Canad. J. Phys. 46, 653 (1968). 